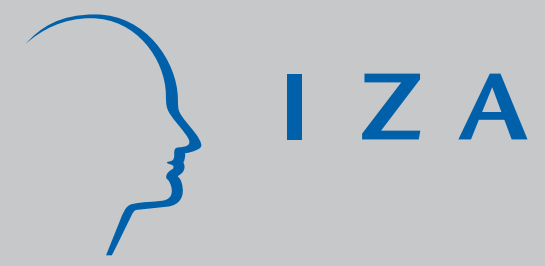

IZA DP No. 5410

Is the Minimum Wage a Pull Factor for Immigrants?

Corrado Giulietti

December 2010 


\title{
Is the Minimum Wage a Pull Factor for Immigrants?
}

\section{Corrado Giulietti}

IZA

\author{
Discussion Paper No. 5410 \\ December 2010
}

\author{
IZA \\ P.O. Box 7240 \\ 53072 Bonn \\ Germany \\ Phone: +49-228-3894-0 \\ Fax: +49-228-3894-180 \\ E-mail: iza@iza.org
}

\begin{abstract}
Any opinions expressed here are those of the author(s) and not those of IZA. Research published in this series may include views on policy, but the institute itself takes no institutional policy positions.

The Institute for the Study of Labor (IZA) in Bonn is a local and virtual international research center and a place of communication between science, politics and business. IZA is an independent nonprofit organization supported by Deutsche Post Foundation. The center is associated with the University of Bonn and offers a stimulating research environment through its international network, workshops and conferences, data service, project support, research visits and doctoral program. IZA engages in (i) original and internationally competitive research in all fields of labor economics, (ii) development of policy concepts, and (iii) dissemination of research results and concepts to the interested public.
\end{abstract}

IZA Discussion Papers often represent preliminary work and are circulated to encourage discussion. Citation of such a paper should account for its provisional character. A revised version may be available directly from the author. 
IZA Discussion Paper No. 5410

December 2010

\section{ABSTRACT}

\section{Is the Minimum Wage a Pull Factor for Immigrants?*}

This paper studies the impact of the minimum wage on immigration. A framework is presented in which inflows of immigrants are a function of the expected wage growth induced by the minimum wage. The analysis focuses on the US minimum wage increase of 1996 and 1997, using data from the Current Population Survey and the census. The estimation strategy consists of using the fraction of affected workers as the instrumental variable for the growth of expected wages. The findings show that States in which the growth of expected wages was relatively large (around 20\%) exhibit inflow rate increases that are four to five times larger than States in which average wages grew $10 \%$ less. Placebo tests confirm that the policy did not affect the immigration of high wage earners.

JEL Classification: J08, J23, J38, J61

Keywords: employment effects, expected wages, immigration, minimum wage, wage effects

Corresponding author:

Corrado Giulietti

IZA

P.O. Box 7240

53072 Bonn

Germany

E-mail: giulietti@iza.org

\footnotetext{
* I am grateful to Dan Hamermesh, Christian Schluter, Mirco Tonin, Jonathan Wadsworth and Jackie Wahba for useful comments.
} 


\section{Introduction}

Does an increase of the minimum wage constitute a pull factor for low-skilled immigrants? A minimum wage set in the receiving country has ambiguous effects on immigration: on the one hand, average wages will increase; but on the other, employment perspectives might be adversely affected. The objective of this paper is to explore this question in the context of the increase in the US federal minimum wage that took place between 1996 and 1997.

There is extensive research about the determinants of immigration, and although it is difficult to define a taxonomy of these factors, there is a consensus that immigrants respond to both economic and non-economic incentives in the receiving country. Relatively favourable employment and wage conditions, along with the presence of network effects, distance from the origin country and immigration policies, are characterised as the principal causes of immigration (Clark et al., 2002; Mayda, 2005). However, research on the role played by labour market institutions, such as the minimum wage, is rather sparse. A minimum wage in the receiving country creates a disequilibrium in the labour market, which may encourage or deter immigration. Economic theory predicts a growth in the average wages of low-wage workers; employment effects are, however, uncertain and depend on the labour market structure (Manning, 2003).

A simple model that relates the minimum wage to immigration is developed and used to estimate the impact of the increase in the US federal minimum wage on the inflows of low-wage workers. The model postulates that migrants take decisions in terms of expected wages, whereby the probability of finding employment is represented by the employment population ratio in the destination country. The change in the minimum wage affects expected wages because it alters both the average wage and the probability of employment. The effects of the policy are analysed using the change in the US federal minimum wage that took place between 1996 and 1997, a period during which both minimum wage impacts and immigration flows exhibited considerable variation across 51 States $^{1}$. The instrumental variable approach implemented in the analysis can effectively be explained in two stages. In the first stage the growth of expected wages is regressed on the fraction of foreign-born individuals who earn between the old and new minimum wage; in the second the predicted values are correlated with changes in the inflow rate of immigrants. The main results show that the $\$ 0.90$ "top-up" in the minimum wage led to an increase in the inflow rate of low-wage immigrants that varies from less than $0.01 \%$ in States with lower growth in expected wages to more than $0.08 \%$ in States where expected wages grew the most. The robustness of these results is tested by including controls for macroeconomic conditions in each State. Furthermore, placebo tests show that the policy did not affect the inflow rates of immigrants earning above the minimum wage.

The paper begins with a literature review of the minimum wage and immigration. The theoretical model and the econometric specification are outlined in Sections 2.3 and 2.4. Section 2.5 provides a description of the data, followed by a factual illustration of immigration and the minimum wage. Section 2.6 presents the results of the estimation along with robustness tests. A brief discussion of the findings and directions for future research conclude the paper.

\footnotetext{
${ }^{1}$ Including District of Columbia.
} 


\section{Minimum wage and immigration}

\subsection{The effects of the minimum wage}

Theories about the effects of the minimum wage can be divided into two strands: researchers who support the classical view, which builds upon the seminal model of Stigler (1946); and a more recent literature strand known as the "new economics of the minimum wage" - named after the influential work of Card and Krueger (1995) - which contradicts the classical textbook framework. The core difference between the two views is the contrasting prediction in terms of employment effects.

The neoclassical model predicts that under a binding minimum wage, firms are constrained to pay higher wages than the market clearing level, and therefore employment would be reduced to the point where the marginal revenue product of labour equals the minimum wage. At this point, more individuals are willing to offer their labour in exchange for the minimum and this determines the level of unemployment. Both wage and employment effects depend on the elasticity of demand and supply. Advances to the classic model of the minimum wage date back to the 1970s, when some interesting extensions were built upon the basic framework, such as the introduction of an uncovered sector (Welch, 1974; Mincer, 1976). Recently, theoretical models have become more structured, with the extension to heterogeneous labour, where the introduction of the minimum wage determines a truncation of the skill distribution (Brown, 1999).

Scholars of the new economics of the minimum wage argue that, due to the existence of frictions in the labour market, moderate increases in the minimum wage may lead to non-negative employment outcomes. Markets may be imperfect because of rigidity in the labour turnover, and the presence of mobility costs or asymmetric information (Manning, 2003). The simplest model of imperfect competition is that of a monopsonistic labour market, with employers having some market power in setting wages. Card and Krueger (1995) build upon the classical monopsony framework and present a search model in which firms offer higher wages in order to discourage turnover. Alternative models of equilibrium wage settings have been developed, but the general implications of such models is that employment effects are not unambiguously negative as predicted by the classical framework ${ }^{2}$.

The contrast in these theories is embodied in the empirical analyses of the minimum wage, which are far from reaching a consensus on the employment effects. Most of these studies focus on teenage workers, and although the target of the studies is always the same - the elasticity of employment with respect to the minimum wage - the methodologies used vary substantially ${ }^{3}$. For example, Card (1992) and Card and Krueger (1995) use the fraction of affected workers to assess wage and employment outcomes of the minimum wage. The fraction of affected workers

\footnotetext{
${ }^{2}$ A comprehensive study is carried out by Manning (2003).

${ }^{3}$ The literature focuses on employment rather than unemployment because the latter is thought to be latent, since the minimum wage exerts, in the first instance, an effect on the labour force participation. If individuals are discouraged to enter or remain in the labour force, the unemployment effects would understate the true effect of the policy. However, the analysis of the employment rate of particular groups is a plausible measure for the labour market effects of the minimum wage, provided adequate control for macroeconomic factors is taken. A comprehensive survey on the minimum wage is conducted by Neumark and Wascher (2006).
} 
is defined as the proportion of a given population that earns between the old and new minimum wage. Using cross-state observations from the Current Population Survey (CPS) for the period just before and after the increase in the minimum wage, the authors show that the fraction of those affected is a valid instrument to explain the "top-up" effect of the law in the average wages of teenage workers. When used to predict changes in employment, the elasticity in most of the cases is close to zero. Neumark and Wascher (1992) are among the first to introduce a state-year design: using observations from the CPS for the period between 1973 and 1989, they find negative values in the employment elasticity for teenagers (between -0.10 and -0.20 ) and young adults (between -0.15 and -0.20). The results of their fixed-effects model are robust to several alternative specifications. Using the same data, Card and Krueger (1995) demonstrate that the findings of Neumark and Wascher are sensitive to the inclusion of the proportion of individuals enrolled in school. By claiming that the enrolment ratio should be excluded from the estimation (since it depends on the minimum wage and not the other way round), they obtain non-negative values for the elasticity. The studies described are the culmination of a long debate about the effects of the minimum wage which still accompanies much of the recent literature.

\subsection{Linking minimum wage and immigration}

One of the first studies to explore the links between minimum wage and mobility is the twosector model of Harris and Todaro (1970), in which the minimum wage is used to explain the persistence of high levels of urban unemployment in some developing countries. This framework assumes that agents decide in terms of expected wages. Workers continue to migrate from the rural sector until the urban expected minimum wage equals agricultural earnings; the excess labour thus remains unemployed.

The only theoretical work which extends the Harris-Todaro framework to the context of international migration is Basu (1995); similarly, the empirical literature that explores this particular link is rather sparse. This is somewhat surprising in light of the fact that welfare benefits are likely to influence the location choice of immigrants, as discussed by Borjas (1999) who shows that immigrants are particularly responsive to welfare programs and that this can partly explain the clustering of immigrants in a few States.

Castillo-Freeman and Freeman (1992) is the only relevant study so far that investigates the relationship between minimum wage and immigration. The authors explore the changes in migration out of Puerto Rico as a consequence of the extension of the US minimum wage to the island. They document that the minimum wage impact has substantially increased over the years, reaching $60 \%$ of the average wage in 1987 (compared to less than $35 \%$ in the US). By analysing migration and inter-industry employment patterns, the authors conclude that the increase of the minimum wage induced a movement of low-skilled workers to the US, preventing high levels of unemployment.

The framework presented in this paper somewhat contrasts that of Castillo-Freeman and Freeman, in that the minimum wage is studied as a pull rather than a push factor. However, as highlighted in their work, "[e]conomic analysis has no clear prediction about how the volume of 
migration might respond to higher minimum wages" ${ }^{4}$. This statement embodies the fact that the effects of the policy are ambiguous; and hence, immigration could increase or decrease as a consequence of the minimum wage. In the next section such ambiguous effects are cast into a theoretical framework that links the policy with changes in immigrants' expected wages.

\section{Theoretical framework}

The key feature of the model is that potential migrants make decisions in terms of expected wages, as in Harris and Todaro (1970). To keep the model as simple as possible, it is assumed that potential migrants belong to two skill groups, high $(h)$ and low $(l)$ skilled. At any time, high-skilled workers earn a wage above the minimum. The immigration flow to each State $j$ at a given time can be represented by the following expression:

$$
m_{j t}^{s}=F\left(\omega_{j t}^{s}, z_{j t}\right)
$$

where $\omega_{j t}^{s}=w_{j t}^{s} e_{j t}^{s}$; the term $\omega_{j t}^{s}$ represents the expected wage of skill group $s$, and $w_{j t}^{s}$ and $e_{j t}^{s}$ are the wage and the employment population ratio of skill group $s \in\{l, h\}$ in the receiving country. The term $z_{j t}$ represents characteristics of State $j$. The migration function has the feature that $F_{\omega}(\omega, z)>0$. At each time, and assuming that the federal minimum wage affects only the average wages, the effect on immigration can be represented by the following expression:

$$
\frac{\partial m_{j}^{s}}{\partial \bar{w}}=F_{\omega} \frac{d \omega_{j}^{s}}{d \bar{w}} .
$$

It is plausible to assume that $\frac{d \omega_{j}^{h}}{d \bar{w}}=0$, i.e., the minimum wage will not affect the labour market of high-skilled workers ${ }^{5}$. The effect of immigration on low-skilled workers will hence depend on the magnitude and sign of $\frac{d \omega_{j}^{l}}{d \bar{w}}$, which can be decomposed into:

$$
\frac{d \omega_{j}^{l}}{d \bar{w}}=\frac{\partial w_{j}^{l}}{\partial \bar{w}} e_{j}^{l}+\frac{\partial e_{j}^{l}}{\partial \bar{w}} w_{j}^{l}
$$

Expression 3 is unambiguously positive only if $\frac{\partial e_{j}^{l}}{\partial \bar{w}}>0$. If this term is negative, the sign and the magnitude depend on the relative impacts of the wage and employment effects. Note that this condition can be rewritten as: $\frac{d \omega_{j}^{l}}{d \bar{w}}>0 \Longleftrightarrow \frac{d e_{j}^{l}}{d w_{j}^{l}} \frac{w_{j}^{l}}{e_{j}^{l}}<1$, i.e., the labour demand elasticity is less than unity. The economic rationale is that the incentive to migrate induced by higher wages might be offset by potential adverse effects on employment prospects.

\footnotetext{
${ }^{4}$ Castillo-Freeman and Freeman (1992, p.189) use this statement in the context of emigration. They discuss that since an increase in the minimum wage implies both a reduction in employment and an increase in wages, less-skilled workers are more likely to emigrate, while relatively more-skilled workers are less willing to move.

${ }^{5}$ It is assumed for simplicity that $F_{\omega}^{l}=F_{\omega}^{h}$, i.e., low- and high-skilled workers react to changes in expected wages with the same magnitude.
} 


\section{Econometric implementation}

The model presented in equation 1 explains the relationship between the changes in immigration flows and the growth of expected wages. This relationship can be cast into an econometric specification that uses variations across States:

$$
\frac{\Delta m_{j}}{P_{j}}=\alpha+\beta \Delta \omega_{j}+\Delta Z_{j}+\varepsilon_{j}
$$

where $\frac{\Delta m_{j}}{P_{j}}$ is the change in the immigration inflow rate, $\Delta \omega_{j}$ represents the growth in the expected wages, and $Z_{j}$ is a set of covariates to control for changes in macroeconomic fundamentals of State $j ; \varepsilon_{j}$ represents a random component. The parameter of interest is $\beta$, which captures the sensitivity of the migration inflows to the growth of expected wages.

Some observations about equation 4 are necessary. First, the specification uses differences, which has the advantage of removing fixed effects that characterize each observational unit (Dustmann et al., 2003). For example, if immigrants move to States with persistent prosperous conditions or where immigrants from the same origin have previously settled, a regression of immigration flows on the minimum wage could hide a spurious relationship or lead to an upward bias in the estimates. Using first differences allows such persistent components to be filtered out. Second, the term $\Delta \omega_{j}$ is endogenous. This is because the growth of average wages and the employment population ratio are simultaneously determined by a change in the minimum wage (Card, 1992), hence creating measurement error in $\omega_{j}$. In addition, immigration flows will lead to a simultaneity bias because they affect equilibrium wage and employment in the destination country. To solve this problem, the expected wages are instrumented by the fraction of affected immigrants, i.e., immigrants who earn between the new and old minimum wage. Card (1992) uses the fraction of affected teenagers because this is thought to be correlated with the change in average wages, but exogenous to changes in employment. He obtains two reducedform equations for changes in wages and changes in employment. This paper builds upon this methodology by combining wage and employment equations into a reduced form for changes in expected wages as a function of the fraction of affected immigrants:

$$
\Delta \omega_{j}=a+\theta B_{j}+v_{j}
$$

It is shown in the Appendix that equation 5 is obtained by exploiting the additive property of OLS. The term B represents the fraction of affected immigrants and $\theta$ captures the causal effect of the minimum wage on expected wages or, more precisely, the semi-elasticity of the expected wages with respect to the fraction of affected workers. Equation 5 is the econometric equivalent of equation 3 , and it is important to note that the parameter $\theta$ combines the effect of the minimum wage on both the changes in average wages and the employment probability in a given period. This can be decomposed into the two effects. Furthermore, it is shown that $\theta$ corresponds to the sum of the semi-elasticity of the two reduced-form equations used by Card (1992) and a mathematical proof of the ambiguity of its sign is given, as previously discussed. The third observation is that the model uses inflow rates, i.e., immigration flows 
divided by the working population in each State before immigration. The use of a relative measure acknowledges the fact that immigration inflows are a function of the size of each State. As a robustness check, results are also presented for the differences in the level of immigration inflows.

A potential issue with the empirical analysis is the possibility that the policy is not exogenous with respect to the macroeconomic conditions of each State. This would be the case of a State minimum wage, where each government may decide to increase the level of the minimum wage in response to some macroeconomic events (for example, very low wages for certain groups of the population). Such a situation could lead to a spurious (perhaps negative) correlation between immigration and minimum wage, because immigrants will tend to move, ceteris paribus, to where wages are higher. This is the reason why the analysis focuses on the federal minimum wage, the implementation of which can be thought to be exogenous to single State conditions.

\section{Data description}

This study focuses on the minimum wage increase that took place in 1996 and 1997. The first increase, from $\$ 4.25$ to $\$ 4.75$, took place in October 1996 , followed by an increase to $\$ 5.15$ in September 1997. The data used come from the monthly CPS for the period 1994 to 1999 and from the 1990 and 2000 censuses. Information on wages, employment status, unemployment and the fraction of affected immigrants is extracted from the CPS. This sample yields a total of more than 10,000,000 individual observations. This enormous amount is required because immigrant cases average just $10 \%$ of the total sample, and wage and employment information is collected only for the outgoing rotation groups (one sixth of the total). Since a limited amount of observations would create noise when deriving observations at the State level, data is pooled over the two years before and after the increase of the minimum wage. Each year starts in October and ends in September ${ }^{6}$. Sample weights are applied to ensure the data is nationally representative.

From the CPS it is possible to derive different measures for hourly earnings. In this paper two measures of hourly wages are used, which are referred to as actual and constructed hourly wages. The actual hourly wages are derived using responses of individuals who report an hourly wage and are paid by the hour ${ }^{7}$. The constructed State hourly wages are obtained using information on the weekly wages of workers paid at a frequency different from hourly and usual hours worked in a week. This measure is likely to be noisy, since both denominator and numerator are measured with error; however, it produces a larger amount of information. Since the effect of minimum wage is measured with higher precision with the actual hourly wages, these will be used as a benchmark in the estimation. Robustness tests will include the results using

\footnotetext{
${ }^{6}$ This particular timing allows the exact period to be captured before the increase of the minimum wage (October 1996). The period after the increase is computed here from October 1997, although the second part of the increase in the minimum wage took place in September. This is done to allow comparability with the period before the increase and to rule out potential seasonal effects.

${ }^{7}$ In unreported results the analysis has also been carried out to include respondents who report an hourly rate but are paid at a different frequency. Inferences are substantially identical.
} 
constructed hourly wages as well. All wages below $\$ 1$ are excluded; values greater than $\$ 30$ and $\$ 40$ are removed for the actual and constructed wages, respectively. This procedure results in fewer than $1 \%$ of observations being censored, and it helps in moderating the measurement error. The growth of wages is defined as the difference of the log average wage before and after the increase of the minimum wage. The fraction of affected immigrants corresponds to the portion of immigrants (over the total reporting wages) who earn between the old (\$4.25) and new (\$5.15) federal minimum wage in the period before the increase. The employment population ratio is defined as the proportion of employed immigrants of the working-age immigrant population in each State. This excludes those aged over 64 and under 16, but includes individuals enrolled in school. The growth of employment is defined as the difference in the log of the employment population ratio. The growth of expected wages is then defined as the product of the growth of wages and the growth of employment. CPS data are also used to compute wage and unemployment changes for the group of prime-age natives in each State, which are used as control variables in some of the specifications.

Data from Census 2000 are drawn from the 5\% Public Use Microdata Samples. These are used to compute immigration flows before and after the increase of the minimum wage. Flows before the increase include individuals who immigrated to the US between January 1995 and December 1996, while flows after the increase contain immigrants who entered the USA between January 1998 and December $1999^{8}$. Flows include only those who report earnings and are classified depending on their hourly wage, which is obtained by dividing the reported earnings by the hours worked in a year ${ }^{9}$.

Since flows are likely to be measured with some error, three different "treatment" groups are defined: I) earnings between $\$ 4.25$ and $\$ 6.50$; II) earnings between $\$ 4.25$ and $\$ 7.15$; and III) earnings between $\$ 3.75$ and $\$ 5.65$. Group I is considered the benchmark for the analysis, since it includes all individuals who earn between the old minimum wage and the highest State minimum wage. The lower bound of $\$ 4.25$ accounts for the presence of sub-minimum wages or imperfect compliance. The upper bound of $\$ 6.50$ is set to include individuals who migrated because of the federal minimum wage but who, after immigration, earn a State minimum wage which is higher than the federal rate and thus binding at the moment of the census ${ }^{10}$. Group II consists of all individuals of group I and of immigrants who might be affected by spillover effects. The upper bound of the group is set at $\$ 2$ above the federal minimum wage and hence captures potential "ripple" effects for individuals who earn a wage that is already $40 \%$ higher than the minimum. Group III includes a wage "window" of $\$ 0.50$ below the old minimum floor and $\$ 0.50$ above the new one ${ }^{11}$.

\footnotetext{
${ }^{8}$ Census data can only be categorized by calendar year. This creates a slight mismatch between CPS and census. However, three months is a plausible gap if immigrants tend to respond to minimum wage changes with a lag because of, for example, a delay in the circulation of information.

${ }^{9}$ The hours worked in a year are calculated using average hours worked in a week and the weeks worked in a year.

${ }^{10} \mathrm{By}$ the end of 1999 the State minimum wage in Massachusetts was $\$ 5.25$; in Alaska, Connecticut, Delaware and Rhode Island \$5.65; in California and Vermont \$5.75; and in Oregon $\$ 6.50$. The Appendix reports the value of the State minimum wage and the dates when the law was introduced.

${ }^{11}$ Robustness checks have also been conducted on the group with earnings between $\$ 4.65$ and $\$ 5.65$ (i.e., $\$ 0.50$ above and below the new threshold). Results are very similar to those for Group III.
} 
Three more groups are created, which include individuals who earn between: IV) $\$ 6.51$ and $\$ 9.00 ; \mathrm{V}) \$ 9.01$ and $\$ 14.00$; and VI) $\$ 14.01$ and $\$ 30.00$. Each of these groups corresponds to roughly one third of the total flows of immigrants who earn wages higher than individuals above group I and are used to implement placebo tests.

Finally, data from Census 1990 come from the tables computed by the USA Census Office and are used to construct variables for the historical immigration used in some specifications.

\subsection{Facts about minimum wage and immigration}

Table 1 presents the characteristics of different groups in the period before the minimum wage increase. The first row reports the fraction of affected workers, defined as the proportion of individuals earning between the old and new minimum wage. Around $15 \%$ of the total population earns wages between $\$ 4.25$ and $\$ 5.14$. When compared to other studies (e.g., Cortes, 2004), this share is relatively high: the reason is that the hourly wages used here are those reported from hourly workers, as this is thought to better capture the impact of the policy.

Table 1: Characteristics of minimum wage earners before the 1996/7 increase

\begin{tabular}{lcccccc}
\hline \hline & Immigrants & $\begin{array}{c}\text { Total } \\
\text { population }\end{array}$ & Women & Blacks & Hispanics & Teenagers \\
\hline Fraction of affected workers & 19.24 & 15.40 & 17.99 & 18.41 & 22.48 & 51.68 \\
Hourly wages & 8.41 & 9.25 & 8.44 & 8.61 & 7.95 & 5.35 \\
Percentage less than high school & 41.16 & 19.02 & 15.79 & 18.53 & 45.06 & 58.75 \\
Working experience & 17.62 & 16.04 & 16.57 & 16.48 & 15.20 & 0.22 \\
Weekly hours worked & 35.03 & 33.28 & 31.07 & 34.03 & 34.93 & 21.53 \\
$\mathrm{~N}$ & 14,914 & 141,715 & 74,215 & 17,786 & 12,896 & 14,675 \\
\hline \hline
\end{tabular}

Source: monthly CPS October 1994 to September 1996. Sample weights are applied. Data refer to individuals aged 16 to 64 who report wages. The group of Blacks also includes mixed groups; Hispanic population corresponds to respondents indicating Hispanic origin, and may be of any race. Potential working experience is calculated according to educational attainment as follows: age minus 17 if less than $10^{\text {th }}$ grade; age minus 18 if between $11^{\text {th }}$ grade and High School Diploma; age minus 19 if some college; age minus 20 if associate degree; age minus 22 if bachelor's degree; age minus 24 if above bachelor's degree.

Immigrants have a relatively high share of affected individuals (above 19\%), which is slightly larger than women and Blacks, but slightly smaller than Hispanics (above 22\%). Teenagers have the largest share of affected workers (above 50\%); this is not surprising given the fact that most young workers under 19 years are employed in industries where the minimum wage is commonplace. Differences in the proportion of affected workers are reflected in the hourly wages of these groups. On average, immigrants earn slightly less than women and Blacks, but roughly $\$ 0.50$ more than Hispanics. The hourly rate for teenagers is the lowest, and corresponds to around $60 \%$ of the population average. Part of the gaps in the share of affected workers and in the hourly wages is attributed to different levels of education. If one excludes teenagers since only a small share of them have completed secondary education - the groups of immigrants 
and Hispanics have the largest share of individuals with educational attainment lower than high school. This proportion is much larger than those of other groups, such as women and Blacks. In terms of working experience and hours worked, however, immigrants report a value slightly larger than other groups (except teenagers, who have basically zero working experience).

In the period under consideration, the share of affected workers differs substantially across the 51 States. This can effectively be seen from Figure 1, which represents the proportion of immigrants who earn between $\$ 4.25$ and $\$ 5.15$ in each State.

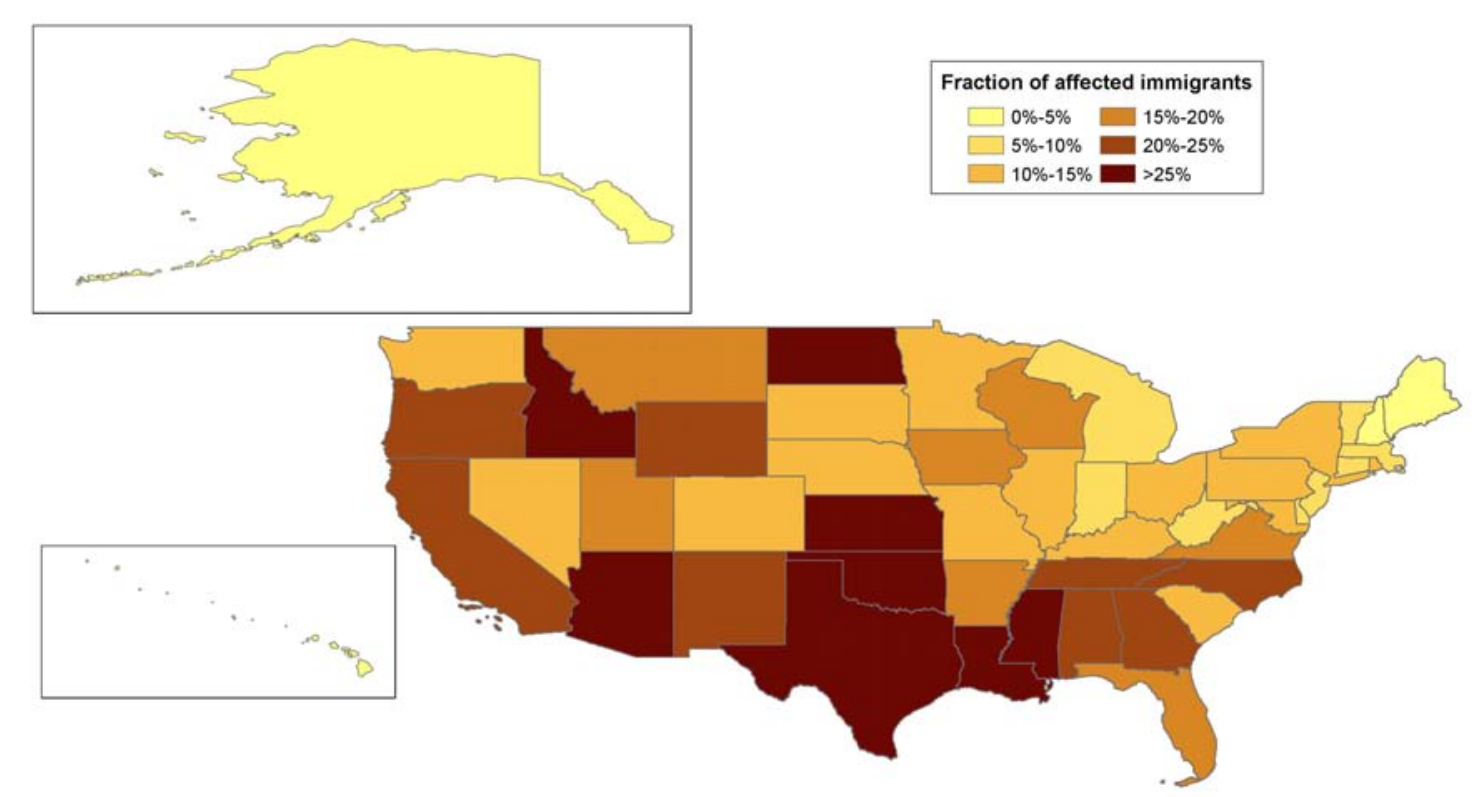

Figure 1: Fraction of affected immigrants in the 51 States Source: CPS. Digital boundaries from http://www.Census.gov/geo/www/tiger/index.html.

In all States of the Northeast region and the Pacific (Alaska and Hawaii), the fraction of affected workers is under $10 \%$. The Midwest region is rather heterogeneous, and shares do not exceed $20 \%$ except in two states (North Dakota and Kansas). Similarly, there are differences in the West region, with values that are, in general, higher than in the Northeast and Midwest. The region with the highest percentage is the South, where the majority of States have a fraction of affected immigrants above $20 \%$. There are several elements that determine these differences. For example, States in the South have generally lower wages than the remaining areas in the US; and States in the West have higher immigration of low-wage workers than in the Northeast and Midwest. The fraction of affected immigrants represents a functional predictor for the impact of the change in the minimum wage. To have a preliminary understanding of the magnitude of the policy, it is useful to compare wages of immigrants before and after the increase. This is done in Figure 2, which represents the kernel wage densities for immigrants in the two periods; the vertical lines indicate the minimum wage before October 1996 and after September 1997. The portion of the density shown in blue contained between the vertical lines represents the nationwide proportion of affected immigrants.

Although the wage distribution does not exhibit the classic "spike" at the minimum wage level, 


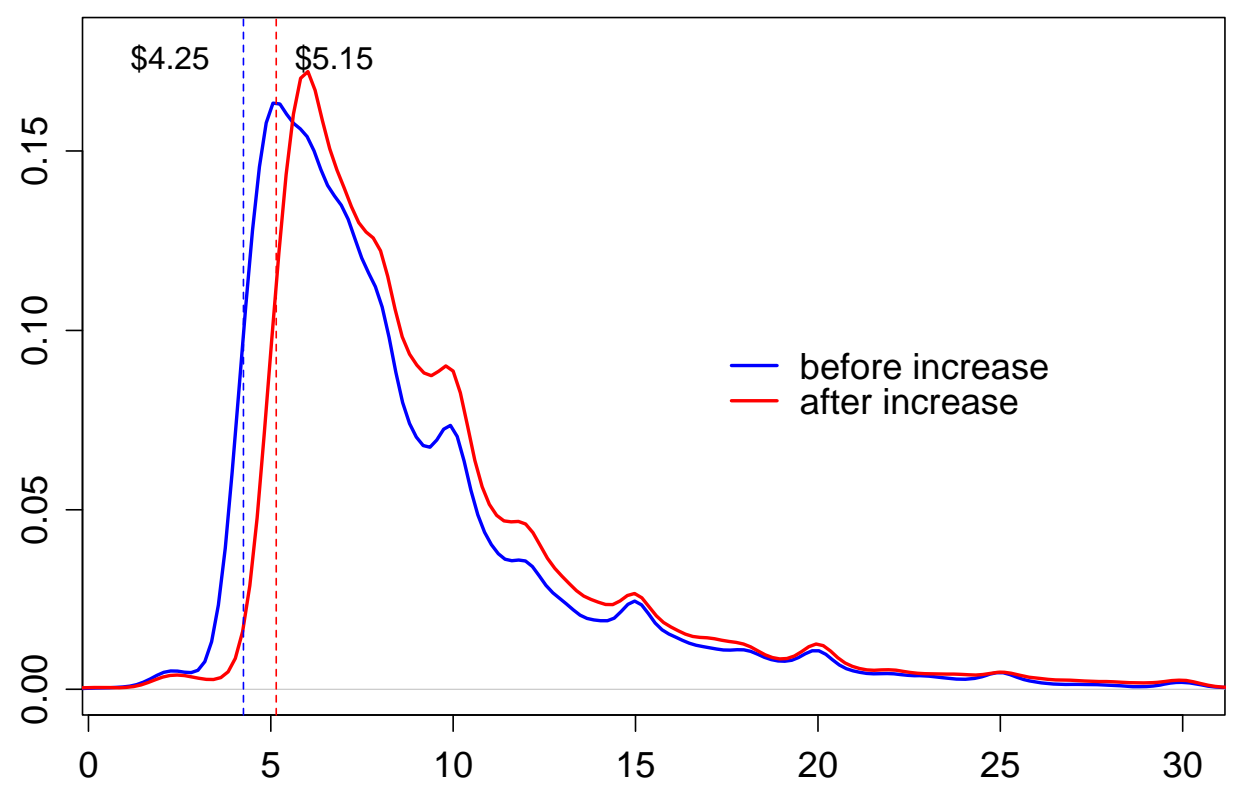

Figure 2: Kernel density of wages before and after the minimum wage increase Source: CPS October 1994-September 1996 (before) and CPS October 1997-September 1999 (after).

the effect of the policy is quite substantial. This is evident from the erosion of the lower part of the wage distribution and the consequent ripple effect that shifts the density to the right. The average wage of immigrants increased from $\$ 8.41$ before the change to $\$ 9.42$ after the new minimum wage was set. Assuming that in the period under scrutiny, the minimum wage was the only determinant of wage growth, the policy determined an increase of around $12 \%$. For comparison, wages of teenagers grew by about $16 \%$ in the same period. This is due to the fact that a larger fraction of teenagers gained from the minimum wage increase, which led to a larger increase in the average hourly wage.

It is insightful to describe what happened to immigration patterns before and after the change of the minimum wage. In the 1990s, as in the previous two decades, immigration to the US increased substantially (Clark et al., 2002). The fact that recent immigrants have tended to concentrate in a few locations where previous immigrants have settled is well documented (Bartel, 1989). However, in the 1990s immigration became less focused and immigrants began to diffuse to a wider range of locations, as is shown in the case of Mexican immigration studied by Card and Lewis (2005). This process of diffusion can be observed through the dynamics of the flows across States.

Table 2 reports the immigration flows before and after the change of the minimum wage both nationwide and for the top 12 destinations ${ }^{12}$. Entries in the left-hand panel refer to immigrants of group I (i.e., low-wage workers), while the right-hand panel reports figures for the total of groups IV, V and VI (i.e., higher-wage workers). For each skill group, the change in the inflow rate (i.e., $\frac{\Delta m_{j}}{P_{j}}$ ) is reported. Although the inflows of both groups increased by about the same amount (90,000 individuals), the dynamics were substantially different. The inflow rate of low-wage workers in the top five States (which are also the major immigration ports of entry)

\footnotetext{
${ }^{12}$ These States represent more than $70 \%$ of total flows in both periods and roughly $53 \%$ of the total working-age population before the minimum wage increased.
} 
increased at a rate similar to the national average, except for New York, where there was a decline of $0.01 \%$. Flows of higher-wage individuals in the top five States, on the other hand, increased by less than the national rate, with the exception of Illinois. In particular, there was a substantial decrease in the flows to New York. The small increase of the inflow rate in the top destinations was balanced by the relatively large growth in other destinations. The growth of the inflows in four States (Georgia, Massachusetts, North Carolina and Virginia) accounted for around one third of the nationwide increase.

Table 2: Immigration in the top 12 destination States, by selected groups

\begin{tabular}{|c|c|c|c|c|c|c|c|}
\hline \multirow[b]{2}{*}{ State } & \multirow[b]{2}{*}{$\begin{array}{c}\text { Working-age } \\
\text { pop in } 1995\end{array}$} & \multicolumn{3}{|c|}{ Group I } & \multicolumn{3}{|c|}{ Groups IV, V and VI } \\
\hline & & $\begin{array}{l}\text { Flows in } \\
1995 / 96 \\
\end{array}$ & $\begin{array}{c}\text { Flows in } \\
1998 / 99 \\
\end{array}$ & $\begin{array}{l}\Delta \text { inflow } \\
\text { rate }(\%)\end{array}$ & $\begin{array}{c}\text { Flows in } \\
1995 / 96 \\
\end{array}$ & $\begin{array}{l}\text { Flows in } \\
1998 / 99 \\
\end{array}$ & $\begin{array}{l}\Delta \text { inflow } \\
\text { rate (\%) }\end{array}$ \\
\hline USA & $166,126,915$ & 273,055 & 360,879 & 0.053 & 905,724 & 996,417 & 0.055 \\
\hline California & $19,966,667$ & 63,895 & 75,999 & 0.061 & 169,467 & 173,519 & 0.020 \\
\hline Texas & $11,940,420$ & 35,373 & 41,814 & 0.054 & 84,650 & 88,466 & 0.032 \\
\hline New York & $11,569,819$ & 28,915 & 27,730 & -0.010 & 101,368 & 87,926 & -0.116 \\
\hline Florida & $8,631,746$ & 28,118 & 33,227 & 0.059 & 84,895 & 83,187 & -0.020 \\
\hline Illinois & $7,477,960$ & 14,599 & 18,308 & 0.050 & 50,528 & 55,811 & 0.071 \\
\hline New Jersey & $5,070,594$ & 11,800 & 14,575 & 0.055 & 45,696 & 47,163 & 0.029 \\
\hline Georgia & $4,667,591$ & 8,050 & 14,142 & 0.131 & 30,356 & 41,184 & 0.232 \\
\hline North Carolina & $4,567,214$ & 6,797 & 13,971 & 0.157 & 23,401 & 31,786 & 0.184 \\
\hline Virginia & $4,243,680$ & 4,505 & 6,831 & 0.055 & 21,637 & 27,675 & 0.142 \\
\hline Massachusetts & $3,887,229$ & 4,470 & 6,590 & 0.055 & 27,080 & 34,080 & 0.180 \\
\hline Washington & $3,462,704$ & 4,794 & 7,474 & 0.077 & 20,886 & 22,912 & 0.059 \\
\hline Arizona & $2,587,427$ & 8,252 & 11,585 & 0.129 & 20,349 & 21,793 & 0.056 \\
\hline
\end{tabular}

Source: flows from Census 2000; population derived from CPS October 1994 to September 1996. Sample weights are applied. Flows before the minimum wage change refer to years 1995 and 1996; flows after the change refer to years 1998 and 1999. All flows consist of immigrants aged 16 to 64 who report earnings in the census.

\section{Analysis}

This section presents the results of the estimation; the subsections report the estimates for the first stage regression (Subsection 6.1), for the second stage (Subsection 6.2) and for the robustness checks (Subsection 6.3).

\subsection{Estimation of the growth of expected wages}

The results from the first stage regression are represented in Figure 3, which plots the growth of expected wages against the fraction of affected workers, along with the regression line and its $95 \%$ confidence interval. The graph also reports the labels of largest immigration States and potential outliers.

The slope of the line - which represents the estimate for $\theta$ - is 0.445 (s.e. 0.110). The explanatory power of the fraction of affected is substantial, given the fact that the $R^{2}$ is about 0.25 . The graph demonstrates that the larger the fraction of affected immigrants, the larger, ceteris 
paribus, the growth of expected wages. Using the additive property of OLS, it is possible to isolate the contributions of the fraction of affected on the wage and employment growth, which are presented in Figure 4. The results of the estimation of equation 5 are given in this subsection. This corresponds to the first stage where the growth of expected wages is regressed on the fraction of affected immigrants. Throughout the analysis, regressions are weighted by the stock of immigrants in each State, which controls for the precision with which observations are measured. Unweighted results are also presented.

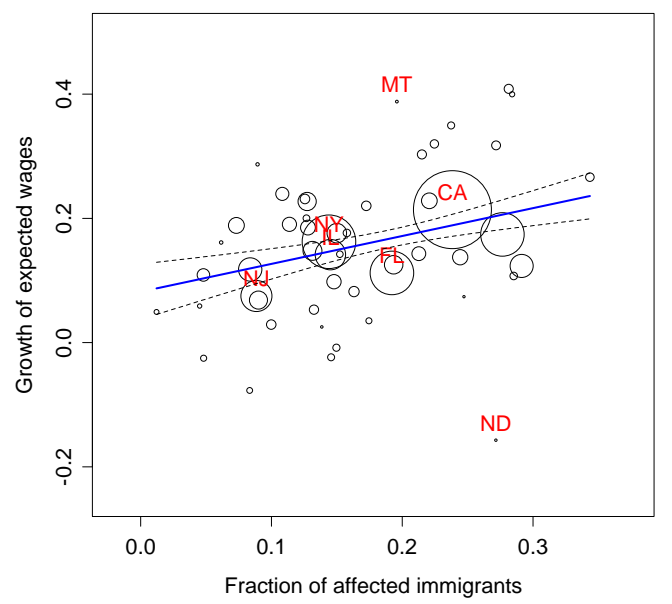

Figure 3: Weighted regression plot of equation 5
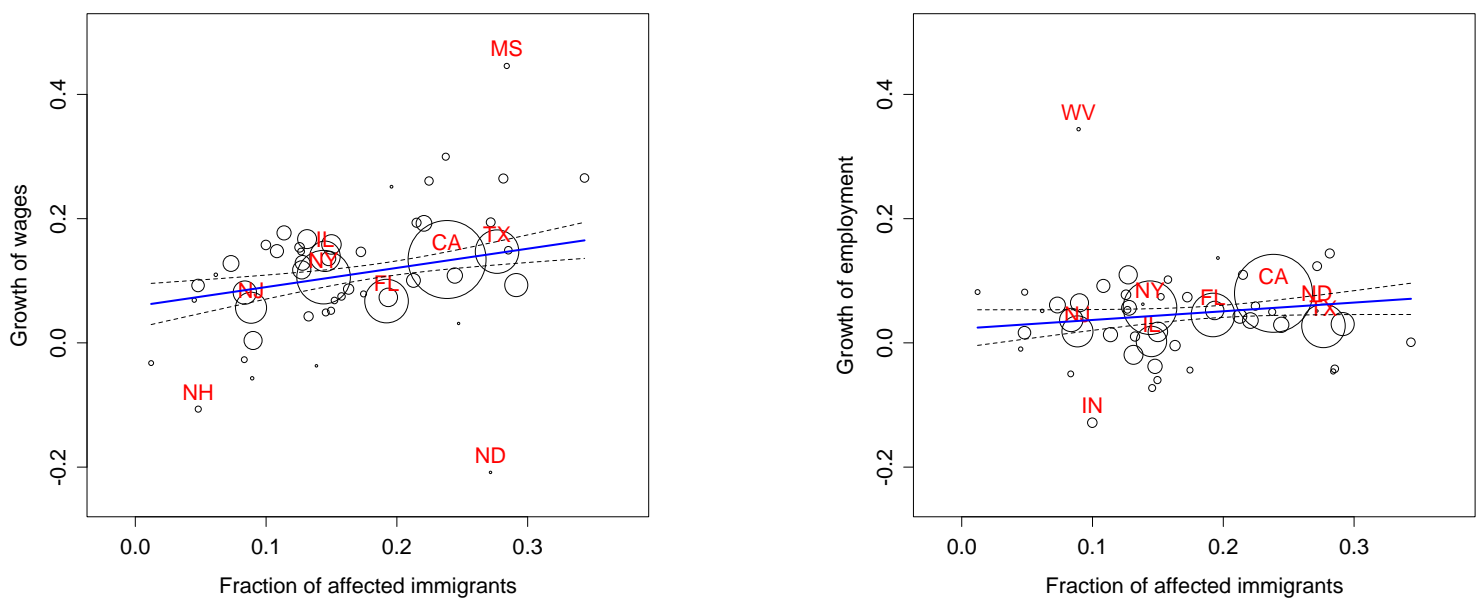

Figure 4: Wage and employment growth and fraction of affected immigrants

The slopes for wage and employment growth are 0.309 (s.e. 0.087 ) and 0.140 (s.e. 0.076 ) respectively, which means that an increase in the fraction of affected immigrants of 0.1 implies a growth of 0.031 for wages and 0.014 for employment. The wage growth overstates the growth of wages in the economy $(16.3 \%)$ and can be attributed to spillover effects. The result for employment growth indicates that in the period under consideration, the minimum wage had positive effects on the employment of immigrants. This result is comparable with the study for consequences on teenage employment by Card and Krueger (1995), although their estimates are 
somewhat smaller. One explanation is that wages of immigrants are affected by factors omitted in the simple regression. Hence, in Table 3, a series of alternative specifications is presented. Column (a) reports the estimates of the parameter $\theta$ for the benchmark case just outlined. Specification (b) is the unweighted regression of model (a); the estimates are 12 percentage points larger than the benchmark. From Figure 4 it can be seen that by ignoring weights, the wage contribution would be much larger, yielding a higher slope. A comparison of the measures of fit suggests that the benchmark model is preferred, as it attributes less weight to outlying observations.

Table 3: OLS regression of expected wage growth

\begin{tabular}{lccccccc}
\hline \hline & $(\mathrm{a})$ & $(\mathrm{b})$ & $(\mathrm{c})$ & $(\mathrm{d})$ & $(\mathrm{e})$ & $(\mathrm{f})$ & $(\mathrm{g})$ \\
\hline Fraction aff. & $0.449^{* * *}$ & $0.578^{* * *}$ & $0.488^{* * *}$ & $0.444^{* * *}$ & $0.434^{* * *}$ & $0.415^{* * *}$ & $0.413^{* * *}$ \\
& $(0.110)$ & $(0.206)$ & $(0.127)$ & $(0.111)$ & $(0.110)$ & $(0.104)$ & $(0.106)$ \\
Unempl. & & & & -0.032 & & & -0.004 \\
& & & & $(0.050)$ & & & $(0.049)$ \\
Wages & & & & & -0.292 & & -0.041 \\
& & & & & & & $(0.247)$ \\
CPI & & & & & & $0.046^{* * *}$ & $0.044^{* *}$ \\
& & & & & & $0.016)$ & $(0.019)$ \\
Constant & $0.082^{* * *}$ & 0.058 & $0.082^{* * *}$ & $0.075^{* * *}$ & $0.105^{* * *}$ & $-0.206^{*}$ & -0.194 \\
& $(0.022)$ & $(0.037)$ & $(0.019)$ & $(0.025)$ & $(0.029)$ & $(0.103)$ & $(0.126)$ \\
$R^{2}$ & & & & & & & \\
$\mathrm{~N}$ & 0.25 & 0.14 & 0.23 & 0.26 & 0.28 & 0.36 & 0.36 \\
\hline \hline
\end{tabular}

Standard errors in parentheses. ${ }^{* * *}$ significant at $1 \%$; ** significant at $5 \%$; ${ }^{*}$ significant at $10 \%$. The reported coefficient refers to the fraction of affected immigrants. All models, except (b), are weighted by the stock of foreign-born population in each State. The macroeconomic controls are all measured in terms of their growth.

Model (c) uses constructed hourly wages, resulting in a coefficient four points larger than in (a). This is explained by the fact that although the average growth of constructed wages is slightly smaller than that of actual wages (10\% vs $12 \%)$, the average fraction of affected immigrants is substantially smaller (14\% vs $19 \%$ ); hence, the coefficient needs to be larger to explain the wage growth.

Models from (d) introduce macroeconomic variables to control for unobserved changes in the economy that could be omitted by the benchmark case. These are the growth of unemployment rate and native wages in each State and the growth of the regional Consumer Price Index $(\mathrm{CPI})^{13}$. Only the CPI is statistically significant in explaining the wage growth of immigrants, but this does not substantially affect the estimate of $\theta$, even when the control variables are jointly estimated. Interestingly, while the growth of the unemployment rate has the expected sign, the wage growth of natives is negative, although it becomes essentially zero when all control variables are included.

The results presented above robustly support the fact that the increase in the minimum wage, as measured by the fraction of affected immigrants, leads to a substantial growth of expected wages. This large increase is attributable to the fact that in the period under analysis, the

\footnotetext{
${ }^{13}$ Historical CPI data are from http://www.bls.gov/cpi/. The values of this index are only available for the four macro regions: West, Midwest, Northeast and South.
} 
minimum wage did not have negative effects on employment. The estimates imply a labour demand elasticity of 0.30 , which is directly comparable with the value of 0.45 derived from the specification in the study by Card and Krueger (1995) which is mostly similar to the one in Table 3. The Appendix reports the derivation of this elasticity. ${ }^{14}$.

\subsection{Estimation of the change in immigration flows}

In this section the second stage of the model is estimated. This corresponds to estimating regression equation 4, with the growth of expected wages instrumented by the fraction of affected workers. The aim is to obtain an estimate of the coefficient $\beta$, which measures the sensitivity of the change of the migration inflow rate with respect to the growth of expected wages.

Before presenting the results of the regression, it is useful to illustrate the problem of endogeneity and the need for using the instrumental variable approach. In Figure 5, the relationship between the growth of immigration inflow rate and the expected wages is presented. On the left is the expected wage growth as calculated from the data (and hence endogenous); on the right is the predicted values from the first stage. In both graphs the regression line and its $95 \%$ confidence interval along with the $95 \%$ prediction bands, are shown. The graphs reveal that if the endogenous variable were used, the relationship would be basically non-existent. However, the relationship becomes positive when the predicted values of the growth of expected wages are used, with an estimate of $\beta$ of about 0.005 (s.e. 0.002). These estimates are insensitive to the exclusion of the outliers represented by the observations outside the $95 \%$ prediction interval.
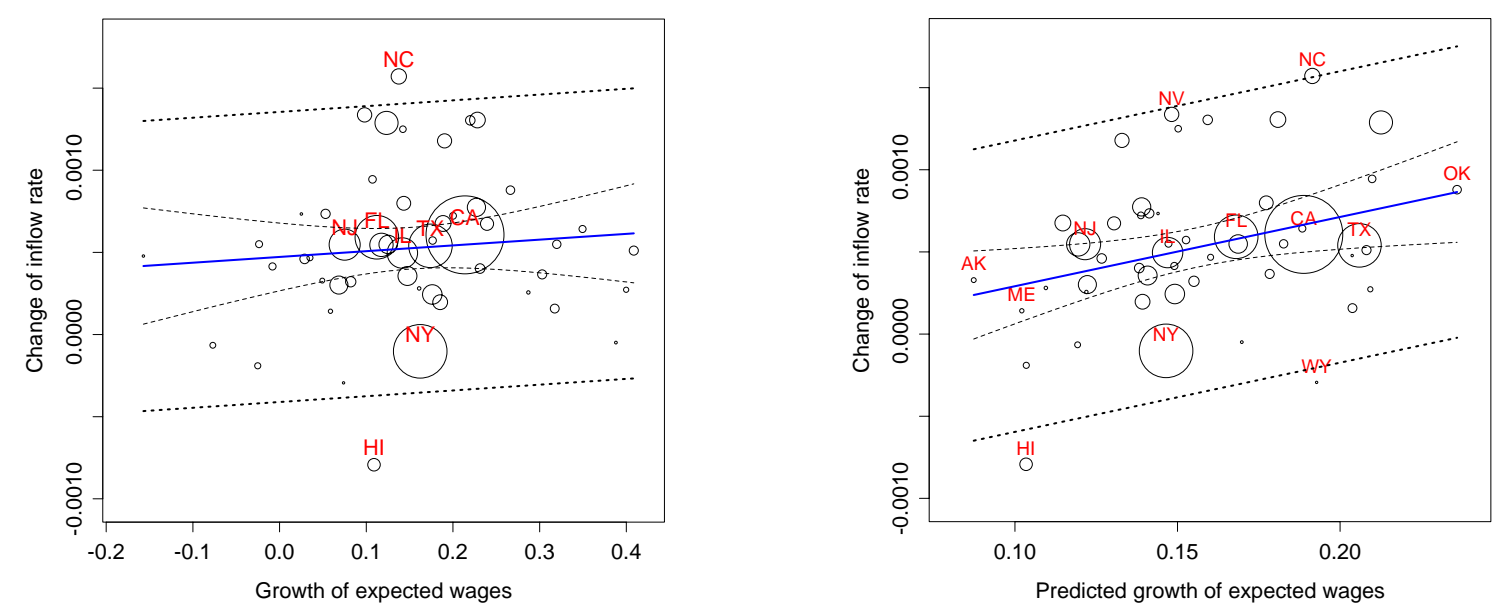

Figure 5: Change in the immigration inflow rate and growth of expected wages

To better understand the economic impact of the estimates, some examples are useful. The average increase in the inflow rate for the wage group I is $0.052 \%$. In States such as Maine, where the predicted growth of expected wages is $10 \%$, the immigration inflow, as fitted by the

\footnotetext{
${ }^{14}$ The value of 0.46 can be derived from the estimates contained in columns (1) and (3) of Table 4.4 panel B, page 128 of Card and Krueger (1995).
} 
regression line, is relatively low (the change was $0.017 \%$ ). In States such as California, where wages grew by about $19 \%$, the regression line predicts an inflow rate change of $0.062 \%$. This means that 9 percentage points of growth in expected wages contributed to an inflow rate change that is $0.045 \%$ larger. In other words, if the expected wages in California had grown by only $10 \%$, there would have been, ceteris paribus, an inflow of about 3,000 low-wage immigrants against the actual 12,000 .

The results of the second stage regression are reported in Table 4 for all models presented in Table 3 and for additional specifications. For illustration purposes, all estimates and standard errors, except those in column (h), are multiplied by a factor of 100 . The comparison of columns (a), (b) and (c) reveals that the unweighted estimates yield a smaller coefficient than the benchmark case; whilst using the measure for constructed wages produces a larger value. However, the introduction of macroeconomic controls does not substantially change the value of the estimates, as can be seen from the models (d) to (g). It is interesting to note that while the wage growth of natives is an important factor in explaining cross-states differences in the change of the inflow rate, the growth of unemployment rate and the CPI are not, although they both have the expected sign. In columns (h) and (i) the specifications for the immigrants in the wage groups II and III are presented. The reported value of $\beta$ for group II is larger than the benchmark case. Since the upper limit of this group is $\$ 2$ larger than the federal minimum wage, it is possible that the presence of spillover effects also attracts immigrants who earn above the minimum wage. Consistently, the coefficient for group III is smaller than that for group I. This can be explained by the fact that the minimum wage window is narrower (the upper limit is $\$ 5.65$ ), and this would exclude all immigrants who were earning the State minimum wage at the moment of the census ${ }^{15}$. Column $(\mathrm{j})$ includes the concentration of immigrants in 1990, defined as the stock of foreign-born divided by the population in each State at the time of the 1990 census. The rationale of adding this variable is to control for the presence of timevarying, migration-related effects that are not captured by using first differences. The estimate of $\beta$ is actually larger than the benchmark case. The coefficient for the historical immigration concentration is negative, although not significant. At first sight, the negative sign might appear a strange result, considering the tendency of new immigrants to move to where previous foreignborn populations had settled. However, it is important to recall that the dependent variable in question is the change in the inflow rates. This means that flows grow relatively more in locations where immigration was historically lower. ${ }^{16}$. This is also documented by Card and Lewis (2005) who find that Mexican immigrants (who represent the largest share of low-wage immigrants) progressively settle away from traditional immigration gateways. Finally, in column (k) inflows rather than inflow rates are used in a regression without weights ${ }^{17}$. It is clear the estimates are not comparable with those of the previous models, but they do constitute a robustness test which demonstrates that even without controlling for population size, the results are similar.

\footnotetext{
${ }^{15}$ For example, California has had a minimum wage of $\$ 5.75$ since March 1998.

${ }^{16}$ On the other hand, flows are highly correlated with historical stocks. For example, a regression of the inflow rate after the minimum wage change (i.e., $\frac{m_{j 1}}{P_{j 1}}$ ) on the 1990 immigration concentration would yield an $R^{2}$ over 0.40 .

${ }^{17}$ When the dependent variable is in the level, weights tend to overestimate the value of the parameter.
} 


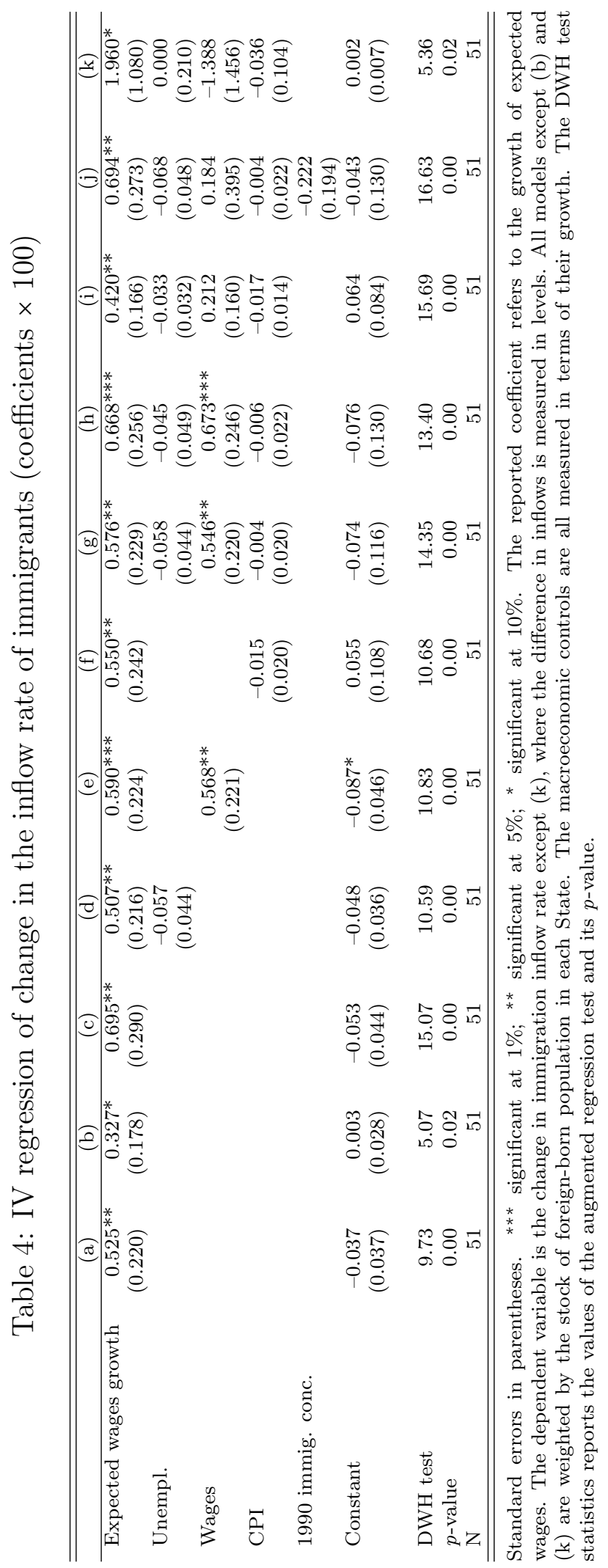


The table also reports the values of the Durbin-Wu-Hausman (DWH) test for endogeneity. The null hypothesis is that the OLS estimator is consistent (under the assumption that the instrument is valid). The test is carried out by augmenting the second stage regression with the residuals of an ancillary regression in which the endogenous variable is regressed on all exogenous covariates (including the instrument). If the parameter accruing to the residuals is significantly different from zero, then the null hypothesis is rejected. As can be seen, the hypothesis that OLS is consistent is strongly rejected in all specifications.

\subsection{Placebo tests}

A counterfactual analysis of the previous results can be obtained by testing the effect of the policy on groups thought to be excluded by the treatment. This section presents placebo tests using the wage groups IV, V and VI. These are groups formed by immigrants who earn a wage higher than the minimum; and hence, other factors, such as the change in macroeconomic characteristics, are expected to explain cross-state differences in their inflow rates. The regressions below present the results for models with and without control variables.

The results consistently demonstrate that the growth of expected wages - as instrumented by the fraction of affected immigrants - is not significant in explaining the change in the inflow rate of immigrants with earnings higher than the minimum wage. However, the growth of prime-age native wages is very important in explaining the change in the inflow rate for groups IV and V, while unemployment is very important for VI. In addition, the CPI has the expected sign only for group IV, but none of the estimates is significant.

Table 5: Placebo tests (coefficients $\times 100)$

\begin{tabular}{lrrrrrr}
\hline \hline & \multicolumn{2}{c}{ Group III } & \multicolumn{2}{c}{ Group IV } & \multicolumn{2}{c}{ Group V } \\
\hline Expected wages growth & -0.058 & 0.011 & 0.073 & 0.106 & 0.092 & 0.064 \\
& $(0.156)$ & $(0.141)$ & $(0.160)$ & $(0.169)$ & $(0.146)$ & $(0.145)$ \\
Unempl. & & -0.013 & & -0.025 & & $-0.087^{* * *}$ \\
& & $(0.027)$ & & $(0.032)$ & & $(0.028)$ \\
Wages & & $0.620^{* * *}$ & & $0.379^{* *}$ & & 0.128 \\
& & $(0.135)$ & & $(0.163)$ & & $(0.140)$ \\
CPI & & -0.001 & & 0.002 & & 0.010 \\
& & $(0.012)$ & & $(0.015)$ & $0.013)$ \\
Constant & 0.000 & -0.000 & -0.000 & -0.001 & 0.000 & -0.001 \\
& $(0.000)$ & $(0.001)$ & $(0.000)$ & $(0.001)$ & $(0.000)$ & $(0.001)$ \\
$\mathrm{N}$ & & & & & & 51 \\
\hline \hline
\end{tabular}

Standard errors in parentheses. ${ }^{* * *}$ significant at $1 \%$; ** significant at $5 \%$; ${ }^{*}$ significant at $10 \%$. The reported coefficient refers to the growth of expected wages. All models are weighted by the stock of foreign-born population in each State. The macroeconomic controls are all measured in terms of their growth. See text for a definition of the wage groups.

\section{Discussion and final remarks}

This paper studies an unexplored aspect of the minimum wage: its pull effect for immigrants. The investigation of the relation between migration and the minimum wage is of particular relevance in the context of recent socio-economic events that have occurred in the US. 
The immigrant population rose systematically during the 1990s, and as of 2000 the share of immigrants exceeded $11 \%$ of the total population ${ }^{18}$. Parallel to these events, the history of minimum wage legislation has also experienced remarkable changes: after a steady decline in the 1980s, the two increases in 1991 and 1992, and 1996 and 1997 have contributed to returning the real value of the minimum wage to the level of 1980 .

There are two main findings in this study: first, the minimum wage in the period under consideration has contributed significantly to the increase of the average wages of immigrants. In addition, there seems to have been a positive effect on employment, and this result supports the hypothesis that there are frictions in the labour market which can be alleviated through the policy. These positive effects on the labour market outcomes have increased the gains that potential immigrants can attain by an average of $15 \%$ (as measured by the increase in the expected wages). The second result is that low-wage immigrants are responsive to the growth of expected wages. This quantity, as instrumented by the fraction of affected workers, robustly predicts cross-section differences in the change of inflow rates. Groups of immigrants who earn more than the minimum wage are instead insensitive to the expected gains produced by the policy.

There is much more to learn about immigration and minimum wages. The empirical analysis in this paper exploits a quasi-natural experiment consisting of an exogenous change in the policy, and hence is focused on the federal minimum wage. However, changes in the federal law are quite rare; and hence, future studies that wish to examine this relation should concentrate on a panel data design which contains data both across States and over time, as conducted in previous studies investigating unemployment effects on teenagers (Burkhauser et al. 2000; Neumark and Wascher 1992). This approach would have two advantages: first, the cross-State data in recent decades have been enriched by the presence of many States which have set their own minimum wage and have different immigration dynamics. The panel data design will be useful to accurately control for State fixed effects. Second, minimum wages effects are also interesting when the nominal wage does not change. The model in this paper predicts that the erosion of the nominal value will lead to a decrease in the expected wages of immigrants. Analysing the consequences on immigration from a decline in the real minimum wage is an interesting question to be explored in light of the fact that the federal minimum had been the same for nearly 10 years ${ }^{19}$. This study will hopefully provide a useful prescription for a better planning of policies related to immigration and the minimum wage. The paper demonstrates the existence of an important relationship, and policies intended to cope with the growing concentration of foreignborn, such as the monitoring of migration levels and the provision of social services, should take into consideration the fact that the minimum wage is an important asset for low-wage earners, capable of inducing them to move from one country to the next.

\footnotetext{
${ }^{18}$ Data from Census 2000. In terms of civilian population, the CPS reveals that this figure is just above $10 \%$, due to different definitions.

${ }^{19}$ The federal rate was recently increased with a new minimum wage bill which established a three-stage increase: $\$ 5.85$ after July 2007; $\$ 6.55$ after July 2008; $\$ 7.25$ by August 2009. This corresponds to an increase in the nominal wage of more than $40 \%$. However, during the past decade several States passed laws that introduced a rate higher than the federal: in 1997 only 7 States adopted their own minimum wage; by 2006 this number was 18 .
} 


\section{References}

Bartel, A. (1989). Where do the New US Immigrants Live? Journal of Labor Economics 7(4), 371-391.

Basu, B. (1995). Minimum Wage, International Migration and Their Effects on Welfare. International Economic Journal 9(2), 101-120.

Borjas, G. (1999). Immigration and Welfare Magnets. Journal of Labor Economics 17(4), 607-637.

Brown, C. (1999). Minimum Wages, Employment, and the Distribution of Income. Handbook of Labor Economics 3, 2101-2163.

Burkhauser, R., K. Couch, and D. Wittenburg (2000). A Reassessment of the New Economics of the Minimum Wage Literature with Monthly Data from the Current Population Survey. Journal of Labor Economics 18(4), 653-680.

Card, D. (1992). Using Regional Variation in Wages to Measure the Effects of the Federal Minimum Wage. Industrial and Labor Relations Review 46(1), 22-37.

Card, D. and A. Krueger (1995). Myth and Measurement: The New Economics of the Minimum Wage. Princeton University Press.

Card, D. and E. Lewis (2005). The Diffusion of Mexican Immigrants During the 1990s: Explanations and Impacts. NBER Working Paper 11552.

Castillo-Freeman, A. and R. Freeman (1992). When the Minimum Wage Really Bites: The Effect of the US-Level Minimum on Puerto Rico. In G. J. Borjas and R. B. Freeman (Eds.), Immigration and the Work Force: Economic Consequences for the United States and Source Areas, pp. 177-212. University Chicago Press.

Clark, X., T. Hatton, and J. Williamson (2002). Where do US Immigrants Come From and Why? NBER Working Paper 8998.

Cortes, K. (2004). Wage Effects on Immigrants from an Increase in the Minimum Wage Rate: An Analysis by Immigrant Industry Concentration. IZA Discussion Paper 1064.

Dustmann, C., F. Fabbri, I. Preston, and J. Wadsworth (2003). The Local Labour Market Effects of Immigration in the UK. Home Office Online Report 06/03.

Harris, J. and M. Todaro (1970). Migration, Unemployment and Development: A Two-Sector Analysis. The American Economic Review 60(1), 126-142.

Manning, A. (2003). Monopsony in Motion: Imperfect Competition in Labor Markets. Princeton University Press. 
Mayda, A. (2005). International Migration: A Panel Data Analysis of Economic and NonEconomic Determinants. IZA Discussion Paper 1590.

Mincer, J. (1976). Unemployment Effects of Minimum Wages. The Journal of Political Economy $84(4), 87-104$.

Neumark, D. and W. Wascher (1992). Employment Effects of Minimum and Subminimum Wages: Panel Data on State Minimum Wage Laws. Industrial and Labor Relations Review $46(1), 55-81$.

Neumark, D. and W. Wascher (2006). Minimum Wages and Employment: A Review of Evidence from the New Minimum Wage Research. NBER Working Paper 12663.

Stigler, G. (1946). The Economics of Minimum Wage Legislation. The American Economic Review 36(3), 358-365.

Welch, F. (1974). Minimum Wage Legislation in the United States. Economic Inquiry 12(3), $285-318$. 


\section{Appendix}

a) Derivation of equation 5

The growth of expected wages can be decomposed into wage and employment growth as follows:

$$
\Delta \omega_{j}^{s}=\Delta w_{j}^{s}+\Delta e_{j}^{s}
$$

where $\Delta w_{j}^{s}$ and $\Delta e_{j}^{s}$ are the log differences of average wages and employment population ratio, respectively. Following Card (1992), the equations for labour demand and the reduced form for wage growth can be defined as:

$$
\begin{gathered}
\Delta e_{j}^{s}=a+\eta \Delta w_{j}^{s}+\nu_{j}^{s}, \\
\Delta w_{j}^{s}=\alpha+\lambda B_{j}^{s}+\zeta_{j}^{s} .
\end{gathered}
$$

The term $B_{j}^{s}$ is exogenous and hence can be used to estimate $\Delta w_{j}^{s}$; the predicted value is then inserted in the equation for the change in employment to obtain:

$$
\Delta e_{j}^{s}=a+\eta \alpha+\eta \lambda B_{j}^{s}+\eta \zeta_{j}^{s}+\nu_{j}^{s} .
$$

To obtain equation 5, substitute A3 and A4 into A1 and use the OLS additive property:

$$
\Delta \omega_{j}^{s}=c+\theta B_{j}^{s}+v_{j}^{s}
$$

where $c=a+(1+\eta) \alpha, \theta=(1+\eta) \lambda$ and $v_{j}^{s}=(1+\eta) \zeta_{j}^{s}+\nu_{j}^{s}$.

b) Derivation of elasticity

The parameter $\eta$ corresponds to the elasticity of the labour demand, $\eta \approx \frac{d\left(\Delta e_{j}^{s}\right)}{d\left(\Delta w_{j}^{s}\right)}$, since:

$$
\begin{gathered}
\Delta w^{s}=\log \left(\frac{w_{1}^{s}}{w_{0}^{s}}\right) \approx \frac{w_{1}^{s}-w_{0}^{s}}{w_{0}^{s}} \\
\Delta e^{s}=\log \left(\frac{e_{1}^{s}}{e_{0}^{s}}\right) \approx \frac{e_{1}^{s}-e_{0}^{s}}{e_{0}^{s}}
\end{gathered}
$$

c) Sign of $\theta$

Appendix a) shows that $\theta$ depends on $\lambda$ and $\eta$; however, the sign is ambiguous. This is because, although the minimum wage has unambiguous positive effect on the average wages (i.e., $\lambda>0$ ), its sign depends on $\eta$.

If $\eta<-1$, i.e., in the elastic part of the demand curve, expected wages decrease because the negative effect on employment more than compensate the positive benefits in terms of wage differentials.

If $-1<\eta<0$, the expected wages react positively to an increase in the minimum wages, but the increase of $\lambda$ will be slowed down, i.e., $\theta<\lambda$. 
If $\eta \geq 0$, the positive effect of employment amounts to that of wages. This only happens if employment changes are not demand-constrained, i.e., are measured along the supply curve, as in the case of monopsonistic labour markets.

\section{d) Mechanism of the fraction of affected immigrants}

For illustration, and following the analysis that Card (1992) conducted for the teenagers, consider how much of the wage increase to comply with the new minimum wage is predicted by the fraction of affected immigrants. The average wage in the economy after the minimum wage change is $\$ 5.23$. This value is larger than the federal minimum wage because during the period under consideration some States passed a law that increased the minimum wage to a value higher than $\$ 5.15$ and thus this weighted average takes into account the different times of the introduction of state and federal laws. The average wage of minimum wage immigrant workers in the period 1994 to 1996 was $\$ 4.71$; in order to comply with the new average minimum wage, average wages had to increase by $11 \%$. Since the average fraction of affected immigrants was about $19 \%$, one would expect wages to grow by $0.11 \times 0.19=2.09 \%$. Instead, the growth of average wages was $11.75 \%$ (from $\$ 8.41$ to $\$ 9.42$ ); average wages grew for other reasons, but at least in the short run, one can assume that these causes were not State-specific. If so, they would have been absorbed by the constant of the reduced form regression of wage growth on the fraction of affected workers. As shown in the text, the regression of equation A3 for wage growth yields a coefficient of the fraction of affected of about 0.31 ; by multiplying this result by the fraction of affected immigrants, one obtains a prediction of wage growth equal to $5.89 \%$. This overestimates the "expected" increase by a factor of $5.89 / 2.09=0.31 / 0.11 .=2.82$. This is somewhat higher than the value found by Card (1992), i.e., $0.15 / 0.088=1.70$. This over-prediction can be ascribed to several factors: inspection of the data reveals that this overestimate is partially attributable to spillover effects.

e) States with different levels of the minimum wage

\begin{tabular}{lcc} 
State & Minimum wage & Date of introduction \\
\hline \hline Alaska & 5.65 & Sep 1997 \\
California & 5.75 & Mar 1998 \\
Connecticut & 5.65 & Jan 1999 \\
Delaware & 5.65 & May 1999 \\
Hawaii & 5.25 & Jan 1994 \\
Maine & 5.25 & Jan 1997 \\
Oregon & 5.50 & Jan 1997 \\
& 6.00 & Jan 1998 \\
Rhode Island & 6.50 & Jan 1999 \\
Vermont & 5.65 & Jul 1999 \\
Washington DC & 5.25 & Jan 1998 \\
\hline \hline
\end{tabular}

